\title{
Corrigendum
}

\section{Corrigendum to "Expression of HGF and c-Met Proteins in Human Keratoconus Corneas"}

\author{
Jingjing You, ${ }^{1}$ Li Wen, ${ }^{1}$ Athena Roufas, ${ }^{1}$ Chris Hodge, ${ }^{1,2}$ Gerard Sutton, ${ }^{1,2,3}$ and Michele C. \\ Madigan $^{1,4}$ \\ ${ }^{1}$ Save Sight Institute, Discipline of Clinical Ophthalmology, The University of Sydney, Sydney, NSW 2000, Australia \\ ${ }^{2}$ Vision Eye Institute, Chatswood, NSW 2067, Australia \\ ${ }^{3}$ Auckland University, Auckland 1010, New Zealand \\ ${ }^{4}$ School of Optometry \& Vision Science, UNSW, Kensington, NSW 2052, Australia
}

Correspondence should be addressed to Jingjing You; jing.you@sydney.edu.au

Received 17 May 2016; Accepted 8 June 2016

Copyright (C) 2016 Jingjing You et al. This is an open access article distributed under the Creative Commons Attribution License, which permits unrestricted use, distribution, and reproduction in any medium, provided the original work is properly cited.

In the article titled "Expression of HGF and c-Met Proteins in Human Keratoconus Corneas" [1], there was an error in the "Acknowledgments" section, which should be corrected as follows:

The authors thank the Medical School of Sydney University, The Ophthalmic Research Institute of Australia (ORIA), Sydney Eye Hospital Foundation, and the Lions NSW Eye Bank for funding support. MCM is funded by the National Foundation for Medical Research \& Innovation (NFMRI).

\section{References}

[1] J. You, L. Wen, A. Roufas, C. Hodge, G. Sutton, and M. C. Madigan, "Expression of HGF and c-met proteins in human keratoconus corneas," Journal of Ophthalmology, vol. 2015, Article ID 852986, 8 pages, 2015. 


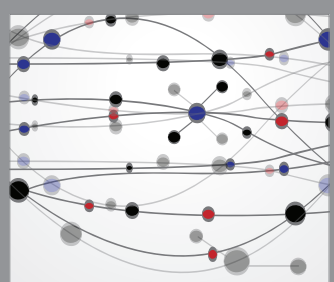

The Scientific World Journal
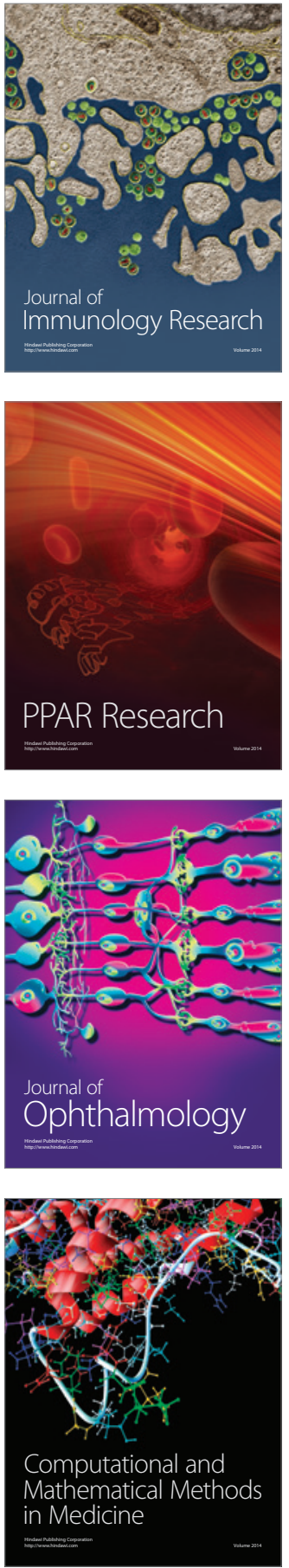

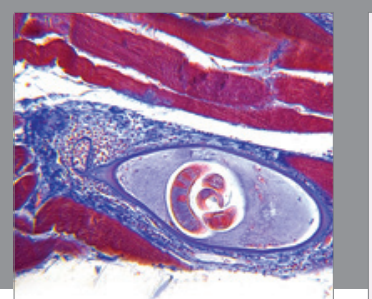

Gastroenterology Research and Practice

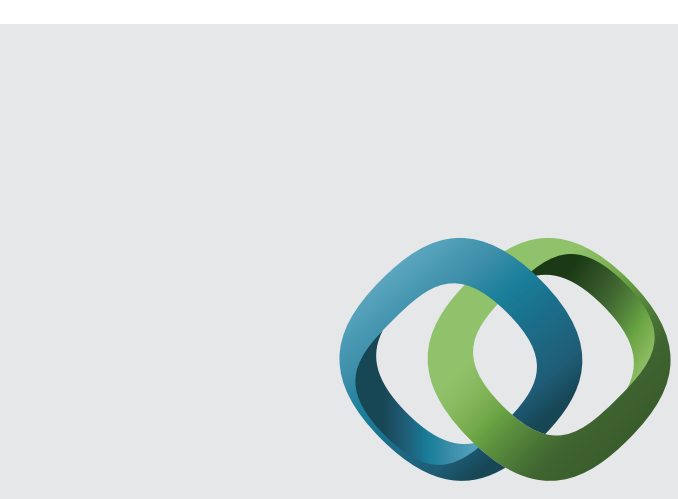

\section{Hindawi}

Submit your manuscripts at

http://www.hindawi.com
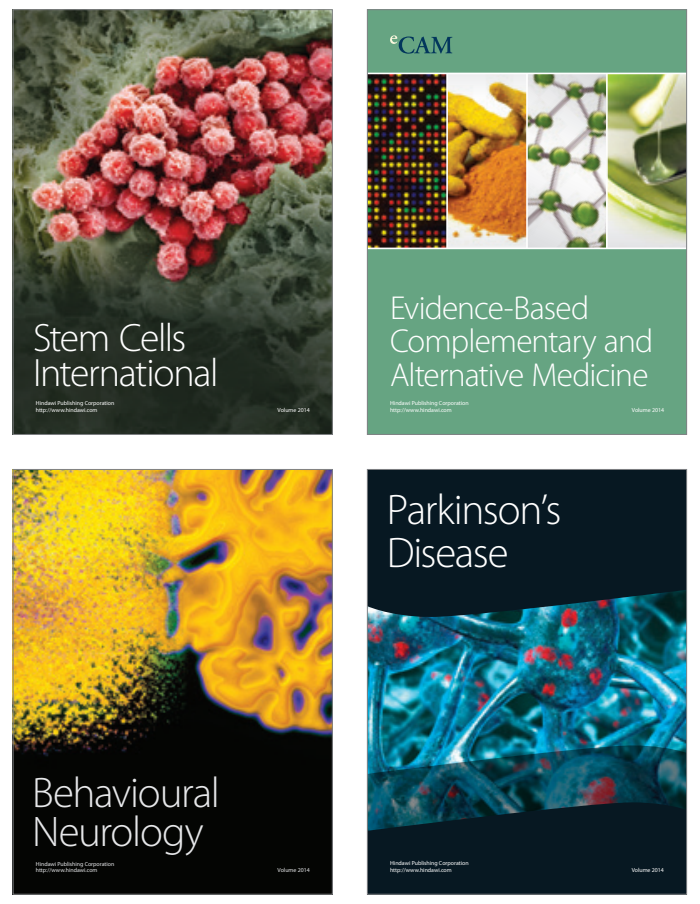
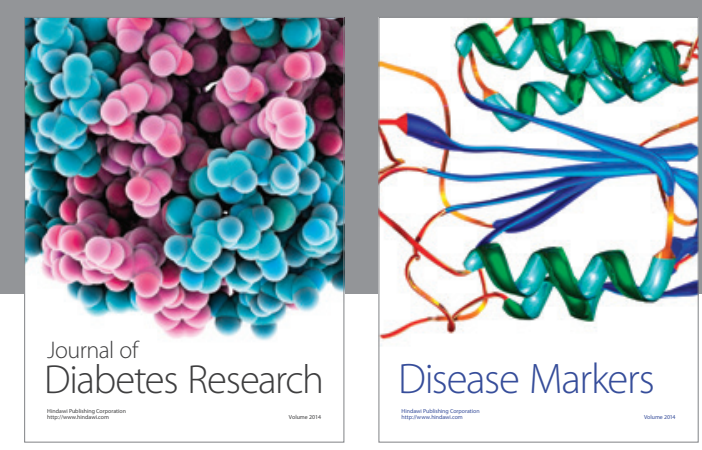

Disease Markers
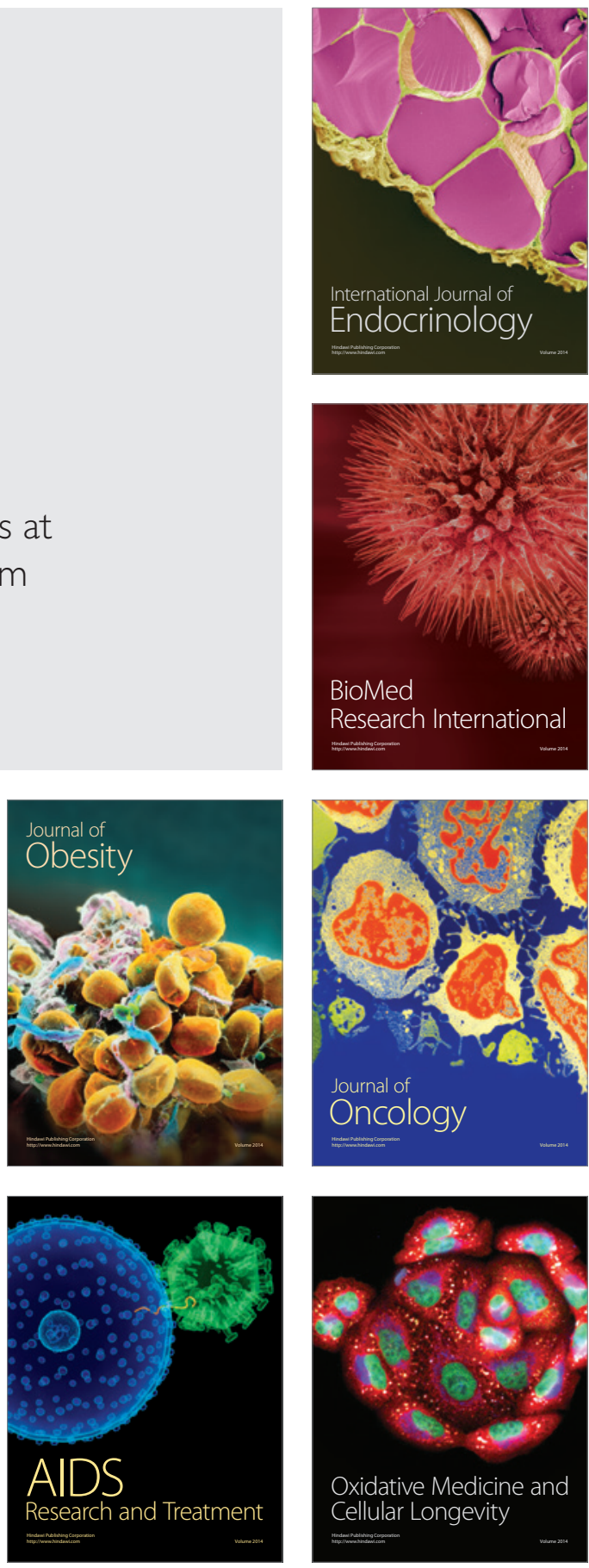